\title{
Charles Gates. "Kinet Höyük (Classical Issos): A Harbor Town in Southeast Cilicia during the Persian and Hellenistic Periods"
}

\section{Astrid Nunn}

\author{
(2) OpenEdition \\ Journals \\ Édition électronique \\ URL : http://journals.openedition.org/abstractairanica/45517 \\ DOI : $10.4000 /$ abstractairanica.45517 \\ ISBN : 1961-960X \\ ISSN : 1961-960X \\ Éditeur : \\ CNRS (UMR 7528 Mondes iraniens et indiens), Éditions de l'IFRI
}

\section{Référence électronique}

Astrid Nunn, «Charles Gates. "Kinet Höyük (Classical Issos): A Harbor Town in Southeast Cilicia during the Persian and Hellenistic Periods" », Abstracta Iranica [En ligne], Volume 37-38-39 | 2018, document 48, mis en ligne le 30 décembre 2018, consulté le 28 septembre 2020. URL : http://

journals.openedition.org/abstractairanica/45517 ; DOI : https://doi.org/10.4000/abstractairanica 45517

Ce document a été généré automatiquement le 28 septembre 2020.

Tous droits réservés 


\title{
Charles Gates. "Kinet Höyük (Classical Issos): A Harbor Town in Southeast Cilicia during the Persian and Hellenistic Periods"
}

\author{
Astrid Nunn
}

\section{RÉFÉRENCE}

Charles Gates. "Kinet Höyük (Classical Issos): A Harbor Town in Southeast Cilicia during the Persian and Hellenistic Periods", Journal of Eastern Mediterranean Archaeology and Heritage Studies 3 (2), 2015, p. 81-104.

1 Le Journal of Eastern Mediterranean Archaeology and Heritage Studies (JEMAHS) est une nouvelle revue scientifique consacrée à l'archéologie traditionnelle, anthropologique, sociale et appliquée de la Méditerranée orientale préhistorique et historique. Elle couvre la Grèce, l'Anatolie, le Levant, Chypre, l'Egypte et l'Afrique du Nord.

Kinet Höyük, situé au fond de la baie d'Iskenderun, se trouve ainsi à la croisée de nombreuses influences et est ainsi un candidat idéal pour cette revue. Les couches les plus anciennes remontent au VI ème millénaire. L'A. se concentre ici sur les 500 ans des époques achéménide et hellénistique, période relativement peu étudiée en Cilicie. Le site a été identifié comme étant la ville d'Issos, près de laquelle Alexandre le Grand vainquit le Roi Perse Darius III en 333 av. J.-C. La période achéménide correspond aux couches 5 (env. 550-450 av. J.-C.), 4 (450-400 av. J.-C.) et 3B (env. 400-330 av. J.-C.). Elle y est bien représentée sous forme d'architecture, de céramique et de petits objets qui reflètent la vie quotidienne d'une ville portuaire. Un grand bâtiment massivement construit se trouvait dans la partie sud (Area U) de la couche 5. L'architecture des deux phases plus récentes consiste en constructions constituées de petites pièces où de la céramique attique fut découverte. Pour une raison inconnue le sommet fut ceint d'une 
fortification à la période 3B. En 2011 il fut possible de fouiller une petite surface (occupée par la British Petroleum) située à $500 \mathrm{~m}$ de la côte. Les murs qui y furent découverts appartenaient très vraisemblablement au port. Outre les fouilles les archéologues tentent de replacer géographiquement chaque étape de la bataille d'Issos.

\section{AUTEURS}

\section{ASTRID NUNN}

Université de Munich 